\title{
A comparative study of Ebola hemorrhagic fever epidemic trends in three West African countries (Guinea, Liberia and Sierra Leone)
}

\author{
Ansoumane Yassima Camara ${ }^{1}$, Lansana Laho Diallo ${ }^{1}$, Moussa Kantara Camara ${ }^{1}$, \\ Mohamed EIMady Camara ${ }^{1}$, Moustapha Kouyate ${ }^{1}$, Sadio Keita ${ }^{2}$, Safere Diawara ${ }^{3}$, \\ Falaye Traore ${ }^{4}$
}

\author{
${ }^{1}$ Department of Medicine, Pharmacy and Odonto-Stomatology, Conakry University, Guinea \\ ${ }^{2}$ Department of Haematology, Donka National Hospital, Conakry - Guinea \\ ${ }^{3}$ Public Health Administrator, Virginia Department of Health, USA \\ ${ }^{4}$ Associate director of the Guinean Institute of Public Health, Conakry - Guinea
}

Received: 28 December 2015

Revised: 12 January 2016

Accepted: 23 January 2016

\section{*Correspondence:}

Dr. Ansoumane Yassima Camara,

E-mail: ayassima@yahoo.fr

Copyright: (C) the author(s), publisher and licensee Medip Academy. This is an open-access article distributed under the terms of the Creative Commons Attribution Non-Commercial License, which permits unrestricted non-commercial use, distribution, and reproduction in any medium, provided the original work is properly cited.

\begin{abstract}
Background: From 2014 to 2015, West Africa has faced an unprecedented Ebola outbreak and the most affected three countries were Guinea, Liberia and Sierra Leone. The purpose of this paper was to analyze Ebola cases in these three Countries and compare the epidemic trends in each country.

Methods: This study was comparative and covered the period from August 2014 to November $24^{\text {th }} 2015$. It is based on statistics provided by each country to the World Health Organization (WHO); which are available on the WHO's website under the title of "situation reports in response to the Ebola outbreak". The paper analysed the trend of probable, confirmed and death cases in each country, and presented various strategies used.

Results: The results shown that combine number of probable and confirmed cases of Ebola virus disease (EVD) was higher in Sierra Leone (8,991 cases) compare to Liberia (5,036 cases) and Guinea (3,804 cases). However, the total number of death was higher in Liberia with 4,808 deaths followed by Sierra Leone with 3,955 deaths, then the Republic of Guinea with 2,536 deaths.

Conclusions: We can retain that the West African Ebola outbreak started in Guinea and stayed there longer, but Sierra Leone had the higher number of confirmed Ebola cases, while Liberia had the highest number of deaths. This epidemic highlighted the weaknesses of different health care systems and the lack of epidemiologic surveillance in these countries. The need to implement a sustainable epidemiologic surveillance system has been underlined.
\end{abstract}

Keywords: Ebola, Outbreak, Guinea, Liberia, Sierra Leone

\section{INTRODUCTION}

The Ebola Virus Disease (EVD) outbreak in West Africa, affected mostly three countries including Guinea, Liberia and Sierra Leone. This paper examined the EVD outbreak in these three countries since they experienced the most widespread transmission. Nevertheless, it should be noted that Nigeria and Mali had noticed a few cases; while, Senegal noticed only one case. Outside of Africa, a few cases landed in the United States (US), Spain, and United Kingdom making the outbreak a real worldwide public health threat. It should be noticed that the epidemic started at the end of 2013 in the forest region of Guinea; which is neighbouring Sierra Leone and Liberia. 
The border line between the 3 countries is presented as parrot's beak that is why this EVD was called an EVD outbreak in the parrot's beak region in West Africa. In these regions, individuals from same ethnic groups live cross borders, same family members maybe distinctly living on both sides of the border, and/or routinely crossing borders for farming. Consequently, people cross borders without any control. These countries have faced the EVD outbreak for the first time with all its corollaries.

These three countries lacked a sustainable health care system since Liberia and Sierra Leone are just rebuilding their health care systems after several years of civil wars. They had untrained health care professionals to face this epidemic and it can be emphasized that none of them was well prepared to confront a deadly disease such as EVD. This outbreak touched three West African countries that have different political situations, different health care systems, and different health care professionals to efficiently respond to such outbreak. The purpose of this article was twofold: (i) analyse EVD cases in the three West African Countries (Guinea, Liberia and Sierra Leone) and (ii) compare the epidemic trends in the three countries.

\section{Ebola outbreaks Review}

In 1976, a hemorrhagic fever outbreak in Southern Sudan and in the Northern of the Democratic Republic of Congo Zaire allowed to isolate Ebola virus; which is the causative agent of a severe form of hemorrhagic fever that is almost endemic in several regions of Central Africa. ${ }^{1}$ Prior researches have suggested possible environmental influence of Ebola fever incidence with a predominant appearance of epidemics at the end of the rainy season and/or the start of drying season. ${ }^{2}$

Usually, Ebola epidemic last from two to nine months and several years passed between outbreak cycles that can be 2 or 8 years. However, in Equatorial Guinea it was experienced about 15-year break period between epidemics in 1976 and 1994-1996, in Democratic Republic of Congo between 1976 and $1995^{2}$, and in Gabon between 1976 and $1996 .{ }^{3}$ It is acknowledged that Ebola virus enters the host through mucosal surfaces, breaks, and abrasions in the skin, or by parenteral introduction. Most human infections in outbreaks seem to occur by direct contact with infected patients or cadavers. ${ }^{1}$

The World Health Organization (WHO), classified Ebola cases as suspected, probable, or confirmed depending on whether they met certain criteria as follow: ${ }^{4}$ (i) A suspected case is any person, alive or dead, who has (or had) sudden onset of high fever and had contact with a suspected, probable or confirmed Ebola case, or a dead or sick animal or any person with sudden onset of high fever and at least three of the following symptoms: headache, vomiting, anorexia/ loss of appetite, diarrhoea, lethargy, stomach pain, aching muscles or joints, difficulty swallowing, breathing difficulties, or hiccup; or any person with unexplained bleeding or any sudden, unexplained death; (ii) A probable case is any suspected case evaluated by a clinician or any person who died from 'suspected' Ebola and had an epidemiological link to a confirmed case but was not tested and did not have laboratory confirmation of the disease; and (iii) A confirmed case is a probable or suspected case which is classified as confirmed when a sample from that person tests positive for Ebola virus in the laboratory.

\section{The three countries profile}

\section{Geography and administration}

The Republic of Guinea, a West African's country, sharing borders with Ivory Coast $(610 \mathrm{~km})$, GuineaBissau (386 km), Liberia $(563 \mathrm{Km})$, Mali $(858 \mathrm{~km})$, Senegal $(330 \mathrm{~km})$ and Sierra Leone $(652 \mathrm{~km})$. It has a coastline on the Atlantic Ocean $(320 \mathrm{~km})$. The Guinean population was estimated in July 2002 at 7,775,065 inhabitants ${ }^{5}$ and in 2014 it was estimated at 12.1 million inhabitants. ${ }^{6}$ Administratively, the country is divided into 33 prefectures and a special zone of Conakry, the capital city with 5 urban communes. Its districts called prefectures are: Beyla, Boffa, Boke, Coyah, Dabola, Dalaba, Dinguiraye, Dubreka, Faranah, Forecariah, Fria, Gaoual, Gueckedou, Kankan, Kerouane, Kindia, Kissidougou, Koubia, Koundara, Kouroussa, Labe, Lelouma, Lola, Macenta, Mali, Mamou, Mandiana, Nzerekore, Pita, Siguiri, Telimele, Tougue and Yomou.

The Republic of Liberia, is located in West Africa, sharing borders with the Republic of Guinea $(563 \mathrm{~km})$, Ivory Coast $(716 \mathrm{~km})$ and Sierra Leone $(306 \mathrm{~km})$ and has a coastline on the Atlantic Ocean $(579 \mathrm{~km})$. Liberia's population was estimated in 2002 at 3,288,198 inhabitants. $^{7}$ The country is divided administratively into 15 counties including: Bomi, Bong, Gparbolu, Grand Bassa, Grand Cape Mount, Grand Gedeh, Grand Kru, Lofa, Margibi, Maryland, Montserrado, Nimba, River Cess, River Gee, Sinoe and Monrovia, the capital city.

The Republic of Sierra Leone is located in West Africa, sharing borders with the Republic of Guinea $(652 \mathrm{~km})$ and Liberia $(306 \mathrm{~km})$, and enjoys $402 \mathrm{~km}$ of the coastline of the Atlantic Ocean. Sierra Leone population was estimated at 5,614,743 inhabitants in 2002. ${ }^{8}$ Administratively, the country is divided into 3 provinces (Eastern, Northern and Southern) and its capital city is Freetown.

\section{Presentation of the health system in the three countries}

Fourteen years of civil war from 1989 to 2003 have contributed to the deterioration of health care system in Liberia. After the conflict, there has been a gradual expansion in humanitarian emergency health actions to accessible areas of the country. It has been recognized 
that the health care system in the country was highly dependent on support from Agencies and NonGovernment Organizations (NGOs); which supported and implemented more than $90 \%$ of the health services delivery. ${ }^{9}$ However, accessibility to basic and secondary health care services was a major problem for more than $75 \%$ of the population due to the challenges reaching referral care services such as essential and emergency obstetric care. The need to strengthen routine epidemiological surveillance, nutritional surveillance, early warning systems, response mechanisms and outbreak investigation systems through improving the capacity of national and local level health systems was highlighted in this previous report.

Eleven years of civil war that ended in 2000, destroyed Sierra Leone health care system and other infrastructures. The government with limited funds struggles to establish electrical power system, clean water supply, and other basic infrastructures; however, it has taken critical steps toward rebuilding capacity and infrastructures in the health sector. ${ }^{10}$ This US Embassy report recognized that among other priorities, rebuilding Sierra Leone's health care infrastructure and health systems should be a priority. In Sierra Leone, global health initiative strategy had already planned several activities before Ebola outbreak as laboratory capacity strengthening effort in order to assist in the diagnosis of lassa fever and other highly infectious diseases in Kenema. There were also discussions with the WHO regarding the challenges of safely managing patients with highly infectious diseases in Sierra Leone. The Lassa Fever Unit project is about building a facility that serves patients requiring isolation. Other functions of the clinic may include the following: Screening and triage of patients, safe clinical care and management, infection control and monitoring, phlebotomy and sample manipulations for safety prior to sending to lab, training and skill building, and clinical research. $^{10}$

In Guinea, the country has been pioneered in implementing the Alma Ata primary care system in the 80 s and the country confidence to its health care system. Despites, the EVD outbreak demonstrated weaknesses of Guinean health care system. Guinea had a pyramidal health care system in place, with 3 national hospitals, 7 regional hospitals, 2 industrial hospitals, a prefectural hospital in each prefecture, 8 communal medical centres and 410 primary health care centers. The country health care system was not prepared to handle an EVD outbreak as its health resources management remained challenging. The poor management of health care systems was highlighted in a report; which established that health resources are badly shared as $48 \%$ of resources were allocated to $20 \%$ of wealthier population and only $4 \%$ were allocated to $20 \%$ of the poorest, and health workers are concentrated in Conakry with $60 \%$ serving only $20 \%$ of the country population. ${ }^{11}$

\section{METHODS}

This study is comparative and based on statistics compiled by the WHO as part of the Ebola hemorrhagic fever outbreak (EHF) situation report in West Africa. ${ }^{12}$ It covered the period from August 2014 to November the $24^{\text {th }} 2015$. In these reports the three forms of diagnosis are reported (confirmed, probable and suspected cases). The paper analysed the trend of probable, confirmed and death cases in each country. Our analyses were presented in graphs and a few statistics was calculated as fatality rates (total number of death over the total number of Ebola cases and multiplied by 100). In this outbreak, the three countries did not report the suspected cases numbers in the same way. Liberia and Sierra Leone used cumulative number of suspected cases. This undermines the fatality rate because most of suspected cases may not be positive to EVD and classified as other febrile diseases, which do not have higher lethality. Therefore, in this paper, the fatality rate was based on the number of deaths over the total number of probable and confirmed Ebola cases, and multiplied by 100 .

We would mention that even though the epidemic started in Guinea at the end of 2013 but WHO started publishing data on its first situation report on March the $28^{\text {th }}, 2014 .^{13}$ Our analyses in this paper started on August the $29^{\text {th }} 2014$ when data were available for the three countries until November the $4^{\text {th }}, 2015$ when data analyses started. ${ }^{12}$

It was decided to select the published WHO situation reports with an interval of one or 2 weeks depending on data availability. In data collected, some data cleaning processes were necessary because a few inconsistencies were noticed. In each report, the cumulative numbers of confirmed and probable Ebola cases, as well as the cumulative death cases were available. Data were checked for data quality issues. For example, it was found that in Liberia's report on October the $15^{\text {th }} 2014$, there were 2,458 cumulative deaths and on October the $31^{\text {st }} 2014$, there were 2413 . We assumed that some deaths were reclassified; therefore October the $15^{\text {th }} 2014$ was not taking into account in our analyses. In Sierra Leone, on October the $31^{\text {st }} 2014$, there was a difference of 120 deaths between probable cases of death for Ebola and probable notified cases of Ebola. These numbers were also reclassified later, but in this study they were not counted. In this paper, we will focus on probable, confirmed Ebola and death cases because suspected cases could be reclassified based on retrospective investigation and based on the availability of lab results and those were not captured in these Ebola situation reports. The suspected Ebola cases cannot be compared across countries since Liberia and Sierra Leone reported the cumulative number of suspected cases and Guinea provided daily number. Data were represented in figures to demonstrate epidemic trend in each country, the Ebola fatality rate was calculated in each country but no statistics measure were used for comparison. 


\section{RESULTS}

The Figure 1 illustrates the Chart comparing the cumulative Ebola confirmed cases between the three countries. Overall, we noted that data were well reported in the three countries. We can notice a regular ascension of the curve in each country with the only exception in Liberia's curve with an abrupt peak in the second half of October in 2014. If in August 2014, the three countries had each less than a thousand cases with 482 cases in Guinea, 322 in Liberia and 935 cases in Sierra Leone, quickly in four months by the end of year, Sierra Leone reached 7,000 cases that shift their curve higher than the 2 other countries.

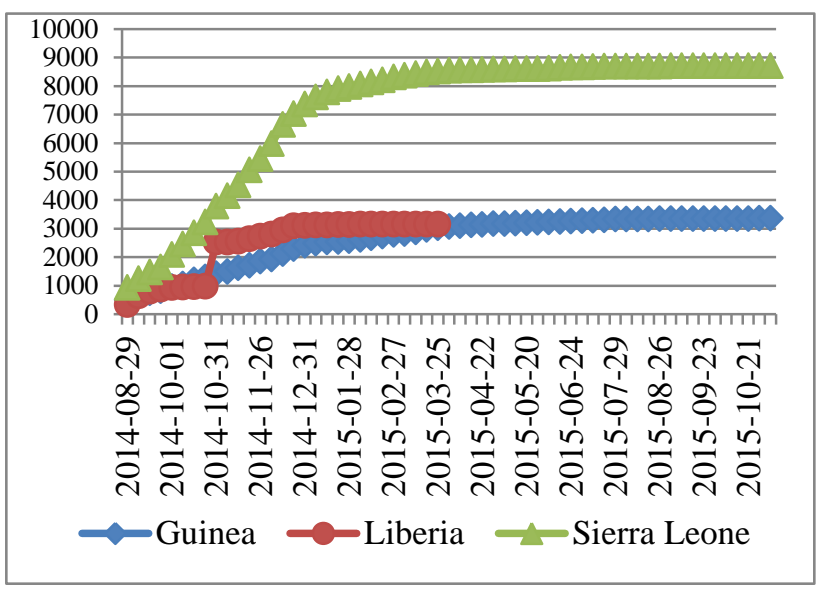

Figure 1: Comparing the cumulative Ebola confirmed cases between the three countries.

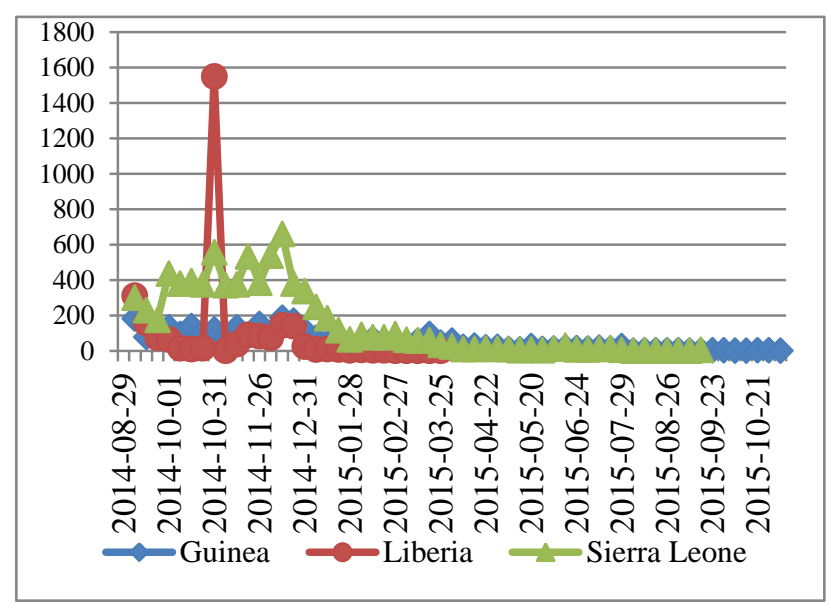

Figure 2: Comparing the daily confirmed Ebola cases between the three countries.

As this graph in Figure 1, Liberia was the first country to be declared Ebola free on May the $9^{\text {th }}, 2015$ after 42 consecutive days past without any new case. However, we should mention that after a 6 weeks lull, on June 29, 2015, Liberia had its first Ebola case since the last case on March the $20^{\text {th }} 2015$. This new cycle developed 6 cases that are not represented in this graph. Then, for the second time in this outbreak Liberia was declared Ebola free on September the $3^{\text {rd }}, 2015$, after the last case was confirmed in laboratory that was associated to Margibi chain. Since that date, Liberia entered the 90 days reinforced surveillance. Unfortunately, on November 17, 2015 three new confirmed Ebola cases were noted in a same family, this new cycle is not included either. How the epidemic ended was not captured in this graph 2. Just to remember that Sierra Leone was also declared Ebola free on November the $7^{\text {th }} 2015$. Up to November the $4^{\text {th }}$ 2015, the cumulative confirmed cases in each country were presented as: 3,351 in Guinea, 3,157 in Liberia and 8,704 in Sierra Leone.

This Figure 2 presents Chart comparing the daily confirmed Ebola cases between the three countries and shows the daily disease burden in each country. It appears that an exceptional peak was reached at the end of October 2014 in Liberia corresponding to the shift in the Figure 1. Thereby, Sierra Leone had seen the number of confirmed cases higher between September and December 2014.

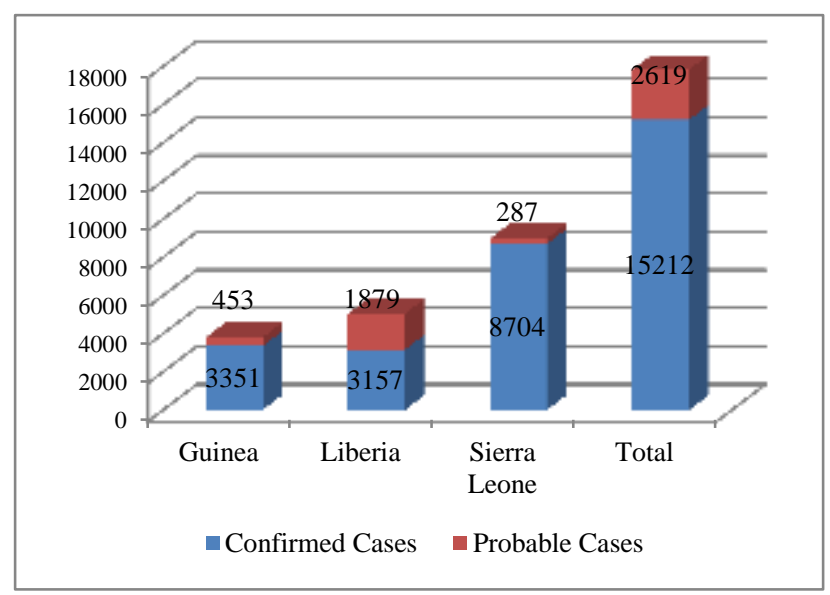

Figure 3: Comparing the number of probable and confirmed cases between the three countries.

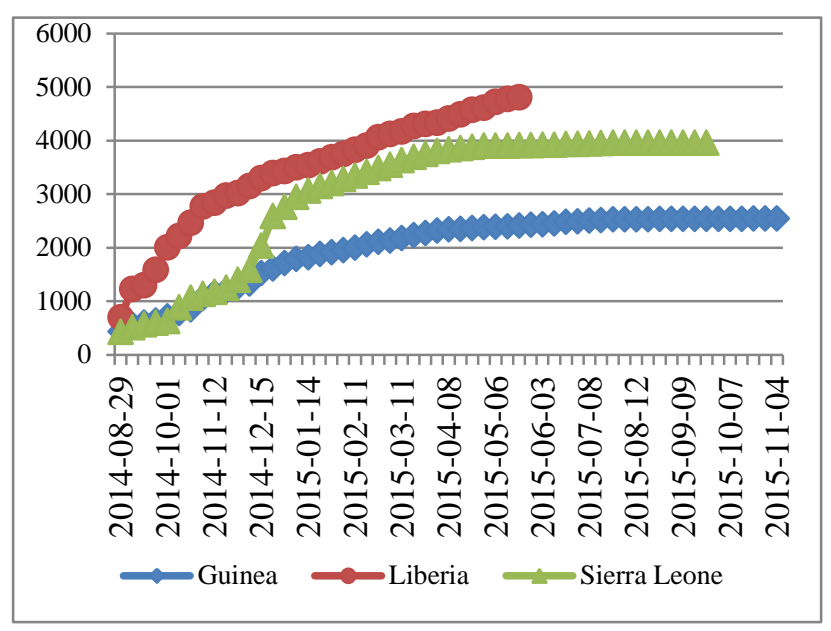

Figure 4: Comparing the cumulative Ebola death data between the three countries. 
In Guinea, the number of confirmed cases has remained steadier between 70 to 180 cases per week until the end of January 2015 and the curve declines to 25 cases back to mid-February 2015 , then increased to 68 cases, and finally decreased toward zero. Since September 2015 the number of new cases is around 0 to 3 cases per week. We can also see that an exceptional peak was reached in Liberia on October the $31^{\text {st }}$, 2015 with 1,549 cases. After the end of 2014, we saw the epidemic decreasing gradually toward zero on March the $20^{\text {th }}, 2015$ that lead to declare the country for the first time Ebola free on May the $9^{\text {th }}, 2015$.

The Figure 3 presents the comparative number of probable and confirmed Ebola cases between the three countries. It is seen that Sierra Leone with 8,991 cumulative probable and confirmed cases of EVD had the highest number, follows by the Liberia with 5,036 cases and the Republic of Guinea with 3,804 cases.

The Figure 4 shows the curves of cumulative number of deaths related to Ebola in the three countries. It appears that the death curve in Guinea seems more regular and increased steadily from 430 deaths in August 2014 to 2,536 cases on November the $4^{\text {th }} 2015$. The curve of Sierra Leone has shown an abrupt increased in December 2014. We can see that Liberia curve remains the highest of the three with 694 deaths in August 2014 to 4,806 deaths on May the $20^{\text {th }} 2015$. Sierra Leone's deaths increased from 422 in August 2015 to 3,955 on November the $7^{\text {th }}, 2015$.

\section{DISCUSSION}

In Sierra Leone the number of confirmed cases was higher between September and December 2014. This can be from the impact of containment strategy used from September the 17th to 19 th 2014 that lead to door to door campaign in order to detect Ebola patients who were hidden in the communities. For this containment, six million inhabitants had to stay home for that period. The operation was reedited from March the $27^{\text {th }}$ to March the $29^{\text {th }}, 2015 ; 2.5$ million inhabitants in Freetown, the capital city and the country Northern part were concerned in order to stem the outbreak. Globally, the frequency of cases detection varied from one week to another. The daily case number varied from 200 to 660 between August 2014 and February 2015, and then decreased toward zero. The last case to receive treatment was confirmed free of Ebola virus disease (EVD) on September the $25^{\text {th }} 2015$ after a second consecutive negative test that is why Sierra Leone was declared Ebola free on November the $7^{\text {th }}, 2015$.

On December the $7^{\text {th }}, 2015$ Guinea had 39 days without any new confirmed case and the last patient in the Ebola Treatment Unit in Forekariah had 2 consecutive negative tests, and then started the rollback count to 42 days to declare the country Ebola free which was done on December 29, 2015. Then the country has entered 90 days reinforced surveillance period that take into account daily alerts communication for febrile diseases, deceases surveillance for secured and dignified burials, Infection Prevention Control (IPC) and reinforcing active research public and private clinics.

The peak reached in Liberia on October the $31^{\text {st }}, 2015$ with 1,549 cases, could not be explained by the effect of particularly virulent virus during this period but rather by the intensification of the awareness campaign and the discovery of suspected cases and the establishment of laboratory confirmation. The Figure 3 shows that Sierra Leone had more than 2 times the number of confirmed Ebola cases compared to Liberia and Guinea but had less number of probable cases. This highlighted the fact that it is in Sierra Leone that the Laboratory service was more efficient and earlier implemented.

The fatality rate was higher in Liberia with $95.7 \%$, follows by the Republic of Guinea with $66,5 \%$ and the Sierra Leone had the lowest rate with $44,0 \%$. It should be noted that these rates cannot be compared directly without referring to each country population and the outbreak region in each country. However, the total number of death was higher in Liberia with 4,808 death followed by Sierra Leone with 3,955 deaths then the Guinean Republic with 2,536 deaths. Since Liberia is lesser populated country, we can see that the country was the most affected by its higher fatality rate.

For implementing the response to the Ebola outbreak, difficulties were higher in Liberia and Sierra Leone because the lacks of reliable health care system. This can explain the weaknesses of these countries' health care system after more than a decade of civil war. Lamstein had suggested six ways to rebuild Liberia's health system: ${ }^{14}$ (i) confident, well-trained health workers, (ii) engaged communities, (iii) a consistent supply chain, (iv) accurate data for decision making, (v) innovative problem solving, and (vi) essential health services provision.

During this West African Ebola outbreak, a number of policies taken by some governments were seen as counterproductive. Several scientists believe that some actions and policies interfere with the right of affected individuals, with a stigma for travelers from affected countries. For example, on November the $17^{\text {th }}, 2014$, over 50 countries around the world had issued travel restriction to and from Ebola-affected countries. ${ }^{15}$ Among other implications, this restriction makes it harder to tackle the disease because the movement of supplies, equipment, and humanitarian aid to affected regions becomes difficult. Isolation of outbreak countries by stopping airlines services and stigmatisation for health workers volunteering in the epidemic regions were criticized. Asgary and colleagues argue against such policies; they questioned evidence and motivations, and discussed their practical and ethical implications in hampering effective responses to EVD in their paper. ${ }^{16}$ We share some authors' opinion who suggested that 
quarantine for suspected travelers from those affected regions who have suggestive symptoms of Ebola infection should be applicable in optimal physical, social and psychological support with health professional following Ebola management protocol. ${ }^{15}$

As in Guinea, numerous strategies were implemented in each of these two other countries as recommended by WHO. ${ }^{17}$ These strategies included: Case isolation and used of personal protective equipment, ban of traditional burial and promotion of security burial with dignity, good ring infection prevention control (IPC), training health care professional, educating population through various social mobilization strategies, and various researches were undergone. The confinement strategy was the only exception used in Liberia and Sierra Leone but not in Guinea. For example, one confinement strategy aimed to keep all Sierra Leone 6 million inhabitants in their houses from the $17^{\text {th }}$ to the $19^{\text {th }}$ of September 2014 to give more time to rescuers and first aid professionals to go from door to door to check for Ebola patients. This containment strategy has enabled the detection of 150 new patients suffering from fever Ebola and 70 corpses.

The confinement strategies that were used in Liberia and Sierra Leone did not show better outcome compared to its implementation difficulties and all the suffering of the population. Guinea relies on population education campaign that had some misfire since the population were very reluctant understanding the given messages with sometime violent responses. Consequently, a team of 9 health professionals, journalists and priests was attacked and killed by outraged population in a rural district of Womey in N'Zerekore.

The partners were almost the same in all three countries but the commitment was different from one country to another due to historical bound. It was visible that England and Canada had more commitment in Sierra Leone, France in Guinea and the United States had taken more leadership in Liberia by sending 3,000 military forces for this outbreak response. All responses to the outbreak were coordinated by the WHO. Several international health institutes provided expertise (the Center for Diseases Control and Prevention (CDC), the Public Health Agency of Canada, Institut Pasteur Dakar, Senegal; the Centre International de Recherche en Infectiologie (CIRI), the Centre International de Recherche en Infectiologie (CIRI), France; the BernhardNocht Institute of Tropical Medicine Hamburg, Germany; the National Institute for Infectious Diseases, Rome, Italy. International non-governmental organisation were represented as Doctors without Borders, Switzerland, Canada, France, Germany, and bilateral (Cuba, Russia, Japan, etc.) and multilateral cooperation with the three countries. Finally, regional and international organisations provided their assistance (the Mano River Organisation, the Economic Community of West African States, the African Union, the European Union, the United States Agency for International
Development, and the Canadian Agency for International Development).

\section{CONCLUSION}

This EVD outbreak highlighted the weaknesses of health care systems in the 3 countries including particularly the lack of reliable public health epidemiologic surveillance. It should be mention that this Ebola outbreak started in Guinea before spreading to other countries and the outbreak longer in Guinea than the two other countries. Sierra Leone had the higher number of confirmed Ebola cases, when Liberia had the highest number of deaths. The outbreak did not happen suddenly as it started, country may have few days of week of lull before a new case could be find. That is why WHO decided the 42 days after the second consecutive negative test of the last Ebola patient in the country to be declared Ebola free. Liberia was two times successively declared Ebola free before getting new cases. We can acknowledge international community mobilisation and assistance in fighting this outbreak. The implication in the three countries was highly appreciated and was essential in overcoming the outbreak. The challenge remains the implementation of sustainable surveillance system in each of these countries. Implementation of CDC operation centers in Guinea and the electronic Disease Early Warning System, based on a mobile application has been introduced in Liberia since December the 7th 2015. These allow lights of hope in the future of epidemic surveillance in the region.

\section{ACKNOWLEDGEMENTS}

This study received no financial support; however, the researchers acknowledged the National Committees of Riposte against Ebola in all three countries who provided the data to WHO for the outbreak long. A special thanks to the WHO which made the statistics available on its website.

\section{Funding: No funding sources Conflict of interest: None declared Ethical approval: Not required}

\section{REFERENCES}

1. Feldmann H, Geisbert TW. Haemorrhagic fever. Lancet. 2011;377:849-62.

2. Pinzon JE, Wilson JM, Tucker CJ, Arthure R, Jahrling PB, Pierre F. Trigger Events: Enviroclimatic coupling of Ebola Hemorrhagic Fever Outbreaks. The American Society of Tropical Medicine and Hygiene. 2004:664-74.

3. Li YH, Chen SP. Evolutionary history of Ebola virus. Epidemiol. Infect. 2013:1-8.

4. WHO. Ebola Response Roadmap Situation Report, 8 October 2014; pp:1-10. Available at: http://apps.who.int/iris/bitstream/10665/136020/1/ro 
admapsitrep_8Oct2014_eng.pdf?ua=1. Accessed October 25, 2014.

5. World Fact Book. Guinea October 2008. http://www.studentsoftheworld.info/infopays/wfb_fr .php3?CODEPAYS=GUI. Accessed March 13, 2015.

6. Université Laval. Guinée 2014. Available at: http://www.axl.cefan.ulaval.ca/afrique/guinee_franc o.htm. Accessed March 12, 2015.

7. World Fact Book. Liberia October 2002. http://www.studentsoftheworld.info/infopays/wfb_fr .php3?CODEPAYS=LBR. Accessed March 13, 2015.

8. World Fact Book. Sierra Leone October 2002. http://www.studentsoftheworld.info/infopays/wfb_fr .php3?CODEPAYS=SLE. Accessed March 13, 2015.

9. WHO and Health action in Crisis. Liberia, Health Sector Needs Assessment. WHO/HAC/SUM/2005.5, 2005.

10. US Embassy Freetow. Global Health Initiative Strategy for Sierra Leone. Freetown: s.n., 2011. pp. 1-49.

11. The Word Bank and Ministry of Health Guinea. Guinea: A Country Status Report on Health and Poverty - Health, Nutrition and Population Inputs for the PRSP and HIPC Process. Conakry. 2006. pp. $1-94$.

12. WHO. Situation reports with epidemiological data: archive. Global Alert and Response (GAR) November 2015. Available at: http://www.who.int/csr/disease/ebola/situationreports/fr/. Accessed November 11, 2015.

13. WHO. Situation Report 1 Ebola virus disease, Guinea, 28 March 2014. 2014. Available at: http://www.afro.who.int/fr/groupes-organiques-etprogrammes/ddc/alerte-et-action-en-cas-depidemieet-de-pandemie/rapports-de-situation/4070-sitrep-1ebola-guinea-28-march-2014.html. Accessed February 25, 2015.

14. Lamstein J. Six Ways to Rebuild Liberia's Health System: What's Next for Liberia. Huff Post Impact What's Working. Available at: http://www.huffingtonpost.com/joel-lamstein/sixways-to-rebuild-liberias-health-system-whats-nextfor-liberia_b_7950952.html. Accessed November 26, 2015.

15. Folayan M, Brown B. Ebola and the Limited Effectiveness of Travel Restrictions. Society for Disaster Medicine and Public Health. Disaster Medicine and Public Health Preparedness, 2015, pp. 92-92.

16. Asgary R, Pavlin JA, Ripp JA, Reithinger R, Polyak CS. Ebola Policies That Hinder Epidemic Response by Limiting Scientific Discourse. Am J Trop Med Hyg. 2015;92(2): 240-1.

17. WHO. Situation Report 2 Ebola Virus Disease, West Africa, 17 April 2014. April 17, 2014. Available at: http://www.afro.who.int/en/clusters-aprogrammes/dpc/epidemic-a-pandemic-alert-andresponse/sitreps/4102-sitrep-2-ebola-virus-diseasewest-africa-17-april-2014.html. Accessed February $27,2015$.

Cite this article as: Camara AY, Diallo LL, Camara MK, Camara ME, Kouyate M, Keita S, et al. A comparative study of Ebola hemorrhagic fever epidemic trends in three West African countries (Guinea, Liberia and Sierra Leone). Int J Community Med Public Health 2016;3:559-65. 